\title{
First contribution to the study of the genus Micatagla Argaman, 1994 (Hymenoptera, Bradynobaenidae, Apterogyninae) in the fauna of Saudi Arabia, with the description of four new species
}

\author{
Neveen Samy Gadallah', Ahmed Mostafa Solimann, \\ Yousif Nasser AlDryhim², Hathal Mohammed Al Dhafer ${ }^{2}$
}

I Entomology Department, Faculty of Science, Cairo University, Giza, Egypt 2 Plant Protection Department, College of Food and Agriculture Sciences, King Saud University, P.O. BOX 2460, Riyadh 11451, Saudi Arabia 3 Zoology Department, Faculty of Science (Boys), Al-Azhar University, P.O. Box 11884, Nasr City, Cairo, Egypt

Corresponding author: Neveen Samy Gadallah (n_gadallah@hotmail.com)

Academic editor: Michael Ohl | Received 26 January 2019 | Accepted 13 June 2019 | Published 28 June 2019

http://zoobank.org/8B7FD9B0-6A7B-4069-9E35-945E1174EB04

Citation: Gadallah NS, Soliman AM, AlDryhim YN, Al Dhafer HM (2019) First contribution to the study of the genus Micatagla Argaman, 1994 (Hymenoptera, Bradynobaenidae, Apterogyninae) in the fauna of Saudi Arabia, with the description of four new species. Journal of Hymenoptera Research 70: 17-40. https://doi.org/10.3897/jhr.70.33381

\begin{abstract}
The species of the genus Micatagla Argaman (Bradynobaenidae: Apterogyninae) in Saudi Arabia are reviewed. A single species, M. antropovi Pagliano, 2002, has previously been reported from Abu Arish (Jazan region, Saudi Arabia). Four new species based on females are described and illustrated in the present paper: $M$. fuscogaster sp. nov. and M. reemae sp. nov. (Garf Raydah Natural Reserve, Asir region), M. saudita sp. nov. (Wadi Hanifah, Riyadh region) and M. similis sp. nov. (Shada Al-Ala Natural Reserve, Al-Baha region). An illustrated key to the females and an annotated faunistic list of all Micatagla species of Saudi Arabia are also provided.
\end{abstract}

\section{Keywords}

faunistic list, females, Micatagla, new species, Saudi Arabia

Copyright Neveen Samy Gadallah et al. This is an open access article distributed under the terms of the Creative Commons Attribution License (CC BY 4.0), which permits unrestricted use, distribution, and reproduction in any medium, provided the original author and source are credited. 


\section{Introduction}

The genus Micatagla Argaman, 1994 is one of the largest genera of Bradynobaenidae and the most speciose in the subfamily Apterogyninae (Pagliano 2002). It currently comprises 54 species (Pagliano 2002, Pagliano and Romano 2013, Gadallah and Soliman 2014, Lo Cascio and Pagliano 2014, Pagliano and Romano 2018). Almost all of them are found in the Afrotropical Region (Pagliano 2002, Lo Cascio and Pagliano 2012). Only four species, M. antropovi Pagliano, 2002, M. ezzati Gadallah \& Soliman, 2014, M. klugi (André, 1899), and M. pseudorainerii Gadallah \& Soliman, 2014, are Palearctic (Pagliano 2002, Gadallah and Soliman 2014).

The genus Micatagla was first proposed by Argaman (1994) in his generic synopsis of Apterogyninae, represented by a single species, M. schultzei (André, 1909). Species of this genus are usually small to medium-sized (4.0-18 $\mathrm{mm}$ in length). They are entirely red (M. schultzei), red mixed with dark ferruginous, or black. Only a few species are entirely black (Pagliano 2002, Pagliano and Romano 2012, Gadallah and Soliman 2014, Lo Cascio and Pagliano 2014). They are characterized by the following: eyes small in female, distant from occipital carina by at least its own diameter; female third metasomal tergite (T3) without yellow spots at base; male hind trochanter with ventral lamella, and brachial cell of fore wing closed, except open in $M$. noorti. Nothing is known about the biology of Micatagla species (Pagliano 2002).

No study has so far focused on the taxonomy of Micatagla in Saudi Arabia. Only two species are known to occur in the whole Arabian Peninsula: M. antropovi (Saudi Arabia, Yemen) (Pagliano 2002), and $M$. hejeki (Yemen) (Lo Cascio and Pagliano 2014). Four new species are described herein: $M$. fuscogaster (Asir), M. reemae (Asir), M. saudita (Riyadh) and M. similis (Al-Baha). An illustrated key to females of all Micatagla species from Saudi Arabia, as well as a faunistic list are also provided.

\section{Material and methods}

The specimens were collected from Riyadh region (Riyadh - Wadi Hanifah), Al-Baha region (Al-Mukhwah - Shada Al-Ala Natural Reserve; Mandaq - Amadan) and Asir region (Abha - Garf Raydah Natural Reserve) (Fig. 1A-C). Sampling was done by means of pitfall trap and some specimens were hand collected around light trap; the collected specimens were pinned directly for identification and further studies. The type materials of the new species are deposited in Efflatoun Bey Collection (EFC), Entomology Department, Faculty of Science, Cairo University, Egypt, and King Saud University Museum of Arthropods (KSMA), Plant Protection Department, College of Food and Agriculture Sciences, King Saud University, Riyadh, Saudi Arabia.

Morphological terms as well as descriptions follow Pagliano (2002). Body sculpture terminology follows Harris (1979).

Photographic images were taken using a Canon EOS 70D attached to LEICA MZ 125 stereomicroscope. Individual source images were then stacked using HeliconFocus 

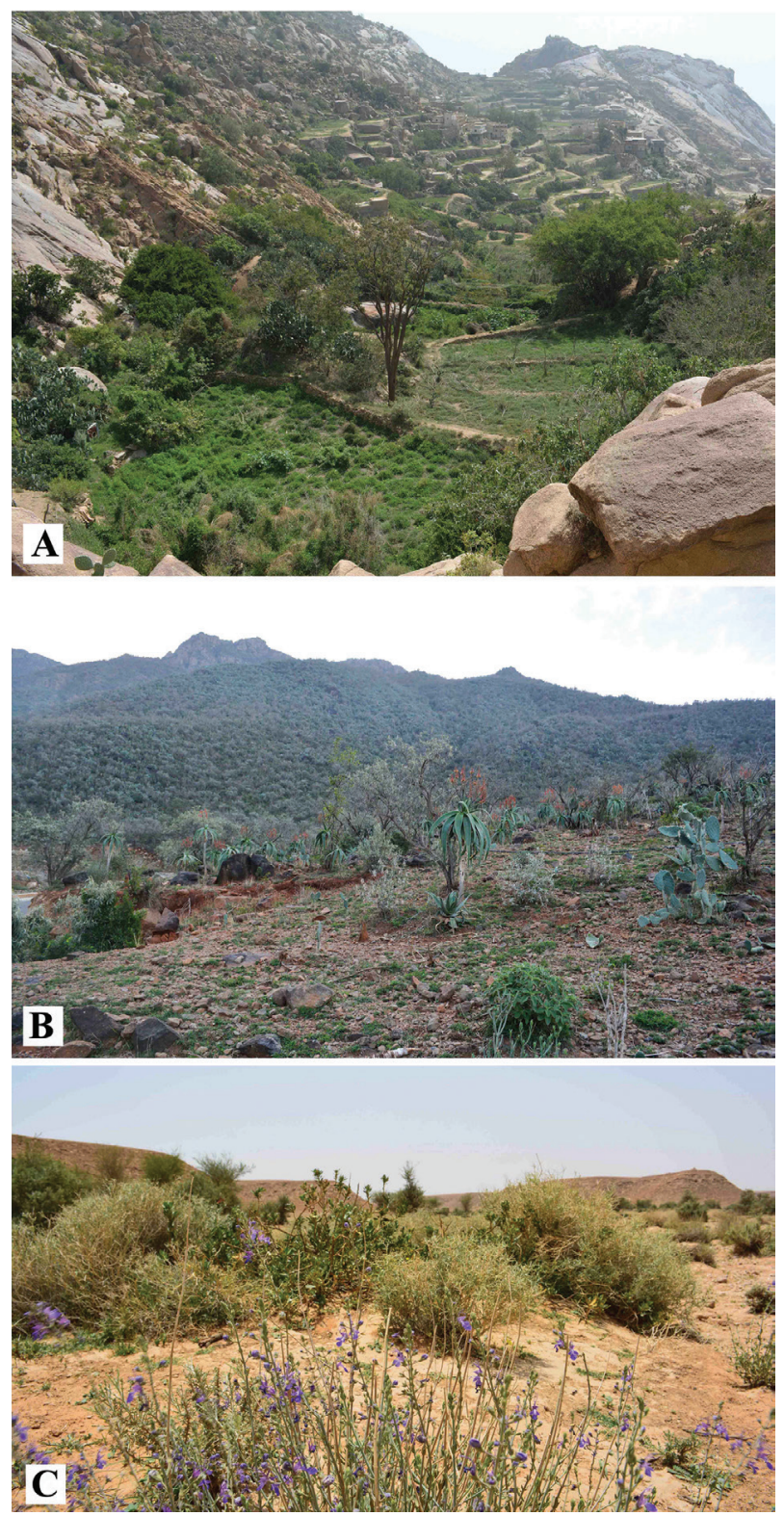

Figure I. Examples of habitat where specimens of Micatagla species (females) were collected. A Shada Al-Ala Natural Reserve (Al-Baha) B Garf Raydah Natural Reserve (Asir) C Wadi Hanifah (Riyadh).

v6.22 (HeliconSoft LTD) extended depth of field software. Further image processing done by using the software Adobe Photoshop Lightroom 5.2 final [ChingLiu]. Measurements were made using an ocular micrometer. The distribution of the collecting sites (Fig. 2) is plotted using DIVA-GIS (v. 7.17). 


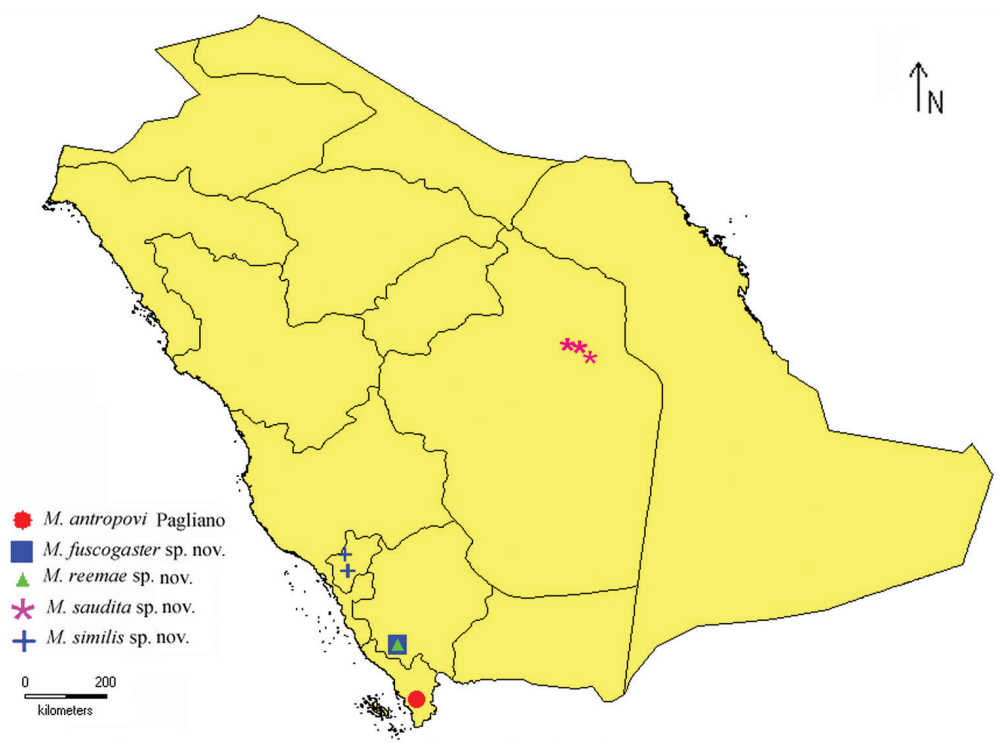

Figure 2. Distributional map of collection localities of Micatagla species in Saudi Arabia.

\section{Collection sites}

Al-Baha Region: Amadan [20 $12^{\prime} 09^{\prime \prime}$, $41^{\circ} 13^{\prime} 54^{\prime \prime E}$, alt. $1881 \mathrm{~m}$ ]. Shada Al-Ala Natural Reserve (Fig. 1A): Cactus 2 [19 $50^{\prime} 24^{\prime \prime} \mathrm{N}, 41^{\circ} 18^{\prime} 41^{\prime \prime E}$, alt. $1611 \mathrm{~m}$ ]; Cac-

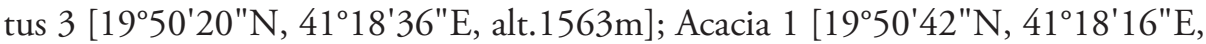

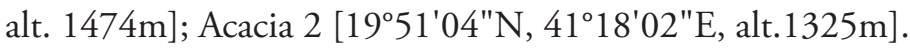

Asir Region: GarfRaydah Natural Reserve (Fig. 1B): Juniper 2 [18 $12^{\prime} 19^{\prime \prime} \mathrm{N}, 42^{\circ} 24^{\prime} 36^{\prime \prime E}$, alt. 2761m]; Juniper 3 [18 $12^{\circ} 06^{\prime \prime} \mathrm{N}, 42^{\circ} 24^{\prime} 32^{\prime \prime} \mathrm{E}$, alt. $2578 \mathrm{~m}$ ]; Olive 1 [18 $11^{\circ} 53^{\prime \prime} \mathrm{N}$,

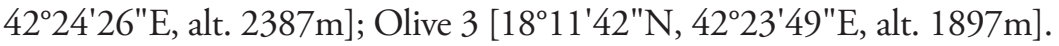

Riyadh Region: Wadi Hanifah (Fig. 1C): WHN01 [2454'19"N, 46¹1'19"E, alt.

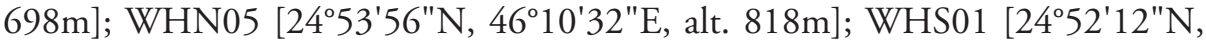

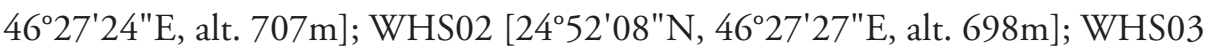

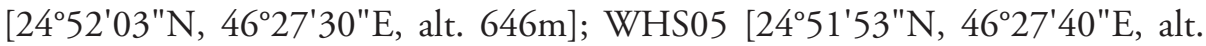
$693 \mathrm{~m}$ ]; WHU02 [243' $40^{\prime \prime} \mathrm{N}, 46^{\circ} 41^{\prime} 18^{\prime \prime} \mathrm{E}$, alt. $584 \mathrm{~m}$ ].

\section{Abbreviations:}

$\begin{array}{llll}\text { F } & \text { antennal flagellomere; } & \text { T } & \text { metasomal tergite; } \\ \text { GRNR } & \text { Garf Raydah Natural Reserve; } & \text { WHN } & \text { Wadi Hanifah, natural habitat; } \\ \text { HP } & \text { hand picking; } & \text { WHS } & \text { Wadi Hanifah, semi-natural } \\ \text { LT } & \text { light trap; } & & \text { habitat; } \\ \text { PT } & \text { pitfall trap; } & \text { WHU } & \text { Wadi Hanifah urbanization } \\ \text { S } & \text { metasomal sternite; } & & \text { habitat. }\end{array}$

SANR Shada Al-Ala Natural Reserve; 


\section{Systematic account}

\section{Key to the species of Micatagla (females) in Saudi Arabia}

1 T4 \& T5 dark reddish brown to blackish brown (Fig. 12A, B); T3 with or without apical faint yellow band (Fig. 12A, B); T2 with sparse posteromedial row of silver setae, absent laterally (Figs 11A, B, 12A, B); eyes weakly bulged laterally when seen from dorsal or frontal views (Figs 6A, B, 7A, B) ............................................... 2

- T4 \& T5 bright red to yellow (Fig. 12C, D); T3 with distinct apical yellow band (Fig. 12C, D); T2 with row of dense silver setae, extending along the whole length of posterior margin (Figs 11C, D, 12C, D); eyes clearly bulged laterally (Figs 6C,

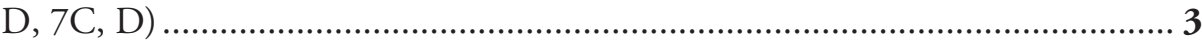

2 Face covered with dense pale setae (Fig. 6A); vertex broadly convex (Fig. 6A); mandible with two, very small teeth subapically; T2 and T3 with coarse ridges between ellipsoid punctures (Fig. 12A); T6 with 10-12 longitudinal close ridges (Fig. $14 \mathrm{~A})$

M. fuscogaster Soliman \& Gadallah, sp. nov.

- Face asetose (Fig. 6B); vertex narrowly convex, semi-rounded (Fig. 6B); mandible edentate (Fig. 6B); T2 \& T3 with fine ridges between ellipsoid punctures (Fig. 12B); T6 with eight longitudinal ridges widely spaced (Fig. 14B).

M. reemae Gadallah \& Soliman, sp. nov.

3 Mesosomal dorsum beyond pronotum striatofoveate (Fig. 9C); metasomal T2 \& T3 with dense, fine close longitudinal ridges, impunctate (Fig.12C); T6 reddish, with darker red lateral and posterior margins, and sparse superficial widely interrupted ridges especially laterally and posteriorly (Fig. 14C); S2 \& S3 reddish, especially apically (Fig. 13C)

M. saudita Soliman \& Gadallah, sp. nov.

- Mesosomal dorsum beyond pronotum foveate-reticulate (Figs 3A, 9D); metasomal T2 \& T3 with dense, opened ellipsoid punctures, ridged in between (Figs 3D, 12D); T6 entirely dark reddish brown, with black longitudinal ridges (either continuous or narrowly interrupted) (Figs 3E, 14D ); S2 \& S3 brownish (Fig 13D) ................... 4

4 Face with bright red to golden setae (Fig. 6D); metasomal tergites with rows of sparse setae apically (Fig. 12D); malar space about $1.3 \times$ as long as eye height (Fig. 8D); T2 \& T3 with broad yellow bands (Fig. 12D); T6 with broadly triangular lateral teeth (Fig. 14D) M. similis Gadallah \& Soliman, sp. nov.

- Face with white setae (Fig. 3B); metasomal tergites with rows of dense setae apically (Fig. 3D); T2 \& T3 with narrow yellow bands apically (Fig. 3D); malar space as long as eye height (Fig. 3C); T6 with sharp lateral teeth (Fig. 3E)

M. antropovi Pagliano, 2002

Micatagla antropovi Pagliano, 2002

Figure 3A-E

Diagnosis. Body clothed with dense white setae (Fig. 3A); mandible bidentate sub-apically (Fig. 3B); metasomal segments with row of dense silvery setae along posterior margins 


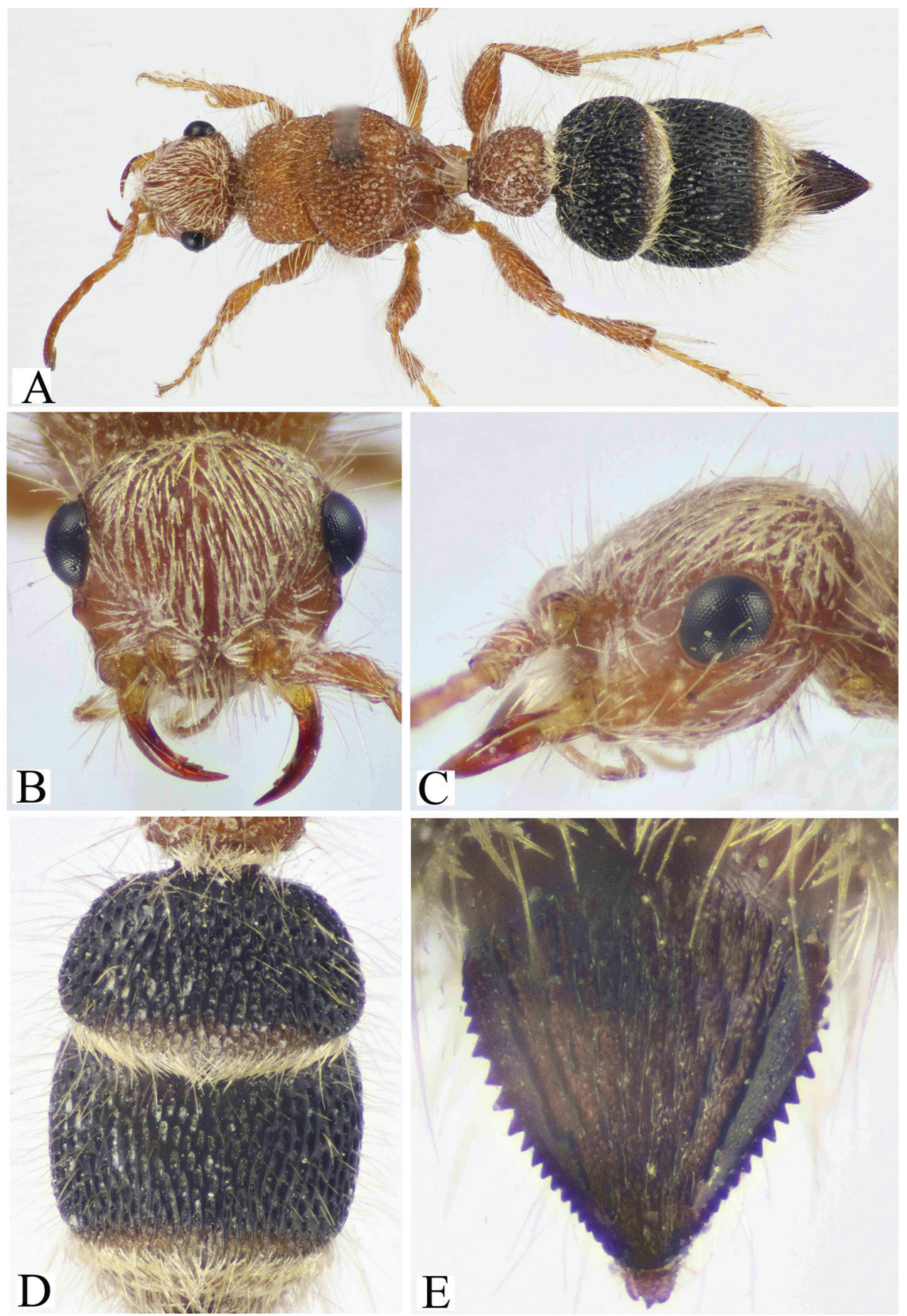

Figure 3. Micatagla antropovi Pagliano, 2002. A Dorsal habitus B frontal view of head C lateral view of head D metasomal T2 and T3 E matasomal T6. 
(Fig. 3D); T2 and T3 black, with interrupted ridges forming deep widely spaced ellipsoid punctures, with thin yellow bands (Fig. 3D); T4 and T5 light yellow; T6 dark brown to black, bordered with large and sharp teeth (Fig. 3E); S2 and S3 deeply punctate-reticulate.

This species is closely related to the new species M. similis Gadallah \& Soliman, from which it may be differentiated by the colour of setae covering face, length of the malar space, the setal density of posterior margin of metasomal tergites, the thickness of the yellow bands on metasomal tergites, and the shape of lateral setae of T6 characters given in the key. It may also be confused with the Egyptian species, M. ezzati Gadallah \& Soliman (Fig. 15) in which the body is smaller in size; mandible edentate (bidentate in $M$. antropovi); colour and sculpturing of T2 and T3, in which they are blackish red (both tergites are black in $M$. antropovi), T2 with ellipsoid punctures and with longitudinal shiny ridges in between, while T3 with fine longitudinal regular ridges (both tergites with interrupted ridges forming deep, widely spaced ellipsoid punctures in $M$. antropo$v i)$; 2 and S3 with widely spaced punctures (deeply punctate-reticulate in $M$. antropovi).

Material examined. 1: Egypt: Fayoum (Kom Osheim), 30.v.2013, leg. Ahmed M. Soliman [EFC].

Previous records from Saudi Arabia. Abu Arish (Jazan region) (Pagliano 2002).

\section{Micatagla fuscogaster Soliman \& Gadallah}

Figures 4A, 5A, 6A, 7A, 8A, 9A, 10A, 11A, 12A, 13A, 14A

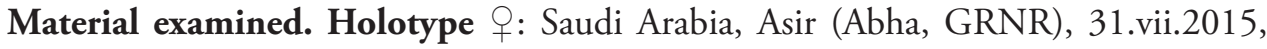
PT4 (Olive 1), leg. Al Dhafer et al. [KSMA]; Paratypes: 19 Saudi Arabia: Asir (Abha, GRNR), 28.iv.2014, PT6 (Olive 3), leg. Al Dhafer et al. [KSMA]; 1 ㅇ Saudi Arabia: Asir (Abha, GRNR), 8.vi.2014, PT6 (Olive 3), leg. Al Dhafer et al. [KSMA]; 1 + Saudi Arabia: Asir (Abha, GRNR), 5.iii.2015, PT3 (Juniper 3), leg. Al Torkey et al. [KSMA]; 1 ㅇ Saudi Arabia: Asir (Abha, GRNR), 31.vii.2015, PT2 (Juniper 2), leg. Al Dhafer et al. [KSMA]; 1 ㅇ Saudi Arabia: Asir (Abha, GRNR), 31.vii.2015, PT4 (Olive 1), leg. Al Dhafer et al. [KSMA]; 1 ㅇ Saudi Arabia: Asir (Abha, GRNR), 31.vii.2015, PT6 (Olive 3), leg. Al Dhafer et al. [KSMA]; 1 ㅇ Saudi Arabia: Asir, (Abha, GRNR), 26.viii.2014, PT (Olive 3), leg. Al Dhafer et al. [EFC]; 1 q Saudi Arabia: same data, 31.vii.2015 [EFC].

Diagnosis. Metasomal segments 2-6 dark reddish brown (Figs 12A, 13A, 14A); T2 with obscured yellow streak (narrow yellow band) posteromesally (Figs 11A, 12A); T1-5 with apical row of sparse setae (Fig. 12A); row of setae on T2 restricted to mesal part along the yellow band, absent laterally (Fig. 12A); T2 and T3 largely ellipsoid punctate, punctures open posteriorly and closer on T2, separated by coarse ridges in between (Fig. 12A).

The new species $M$. fuscogaster Soliman \& Gadallah resembles the South African species M. ellipsigera (Invrea) in having T2 and T3 with greatly reduced apical yellow bands, and T4 and T5 dark reddish brown to black. However, it differs from it in having T2 bell-shape, $1.45 \times$ as wide as long (T2 very transverse in M. ellipsigera, $2.5 \times$ as wide as long); metasomal tergites with apical row of sparse setae (lacking in 
M. ellipsigera); T2 and T3 on disc strongly and irregularly ridged, with large ellipsoid setiferous puncture in between (in M. ellipsigera T2 and T3 finely longitudinally striated, denser and more parallel on T3).

Description. Female (Holotype). Body length $6.6 \mathrm{~mm}$.

Colour (Figs 4A, 5A, 12A, 14A): Head (including antenna), mesosoma, legs and first metasomal segment red, head significantly dark red; remaining metasoma dark reddish brown, with faint yellow band restricted to posteromesal part of T2; S2 with red tint; T6 with black longitudinal ridges; maxillary and labial palpi yellowish red; mandible reddish brown, red basally; fore tibial spur red, mid and hind ones waxy white.

Pubescence (Figs 6A, 7A, 10A, 12A): Body including scape of antenna and legs clothed with long erect white setae that are procumbent on face; T1-5 with row of weak silvery setae, directed towards middle; row of setae of T2 restricted to mesal part along the yellow band only, absent laterally.

Head (Figs 6A, 7A, 8A): Dorsally scarcely wider than the pronotum (about $1.1 \times$ ), nearly as wide as the maximal width of mesosoma at mesopleuron, with thin and sharp occipital carina; face and vertex with relatively large, deep setiferous punctures, about 0.5-1.0 diameter apart, denser near inner margin of eyes; vertex broadly convex; eye relatively small, weakly bulged laterally when seen in dorsal or frontal views, located slightly above mid line between clypeus and vertex when seen in front view; distance between antennal tubercles slightly less than tubercle length; malar space about as long as eye height; scape of antenna about $2.3 \times$ as long as F1; F1 slightly longer than F2 (about $1.15 \times$ ). Clypeus broad, densely punctate basally, with slightly emarginate free margin; mandible relatively thick, with very small two teeth subapically.

Mesosoma (Figs 9A, 10A): Pronotum distinctly wider than long at its maximum width $(1.65 \times)$, densely setiferous foveate dorsally, rugose or faintly wrinkled laterally, with anterior margin gently declivous, humeral angle rounded and posterior margin broadly concave; remainder of mesosomal dorsum densely setiferous foveate-reticulate, foveae larger than those on pronotum; posterior face of propodeum gently declivous (oblique), somewhat smooth and impunctate; mesopleuron superficially foveolate especially anteriorly; metapleuron smooth above, and weakly transversely ridged below; outer hind tibial spur about $0.65 \times$ as long as related hind basitarsus.

Metasoma (Figs 11A, 12A, 13A, 14A): T1 pear-shape, scarcely wider than long $(1.1 \times)$, densely setiferous foveate; T2 bell-shape, about $1.45 \times$ as wide as long, with faint yellow band posteromedially, slightly widened medially; T2 and T3 on disc longitudinally ridged, more distinct on T2, with large ellipsoid setiferous puncture in between, punctures are opened posteriorly, both tergites are densely foveate laterally; T4 and T5 finely alutaceous, with rows of coarse and very close setiferous punctures posteriorly; T6 basally with 10-12 longitudinal widely spaced ridges, roundly pointed at apex, with relatively large and blunt teeth laterally, gradually smaller from base to apical end of the tergum. S2 and S3 with dense punctures mainly laterally and medially, leaving posterior margins smooth and shiny pre-apically, S2-5 with row of long setae along posterior margins; S4-6 smooth and shiny. 

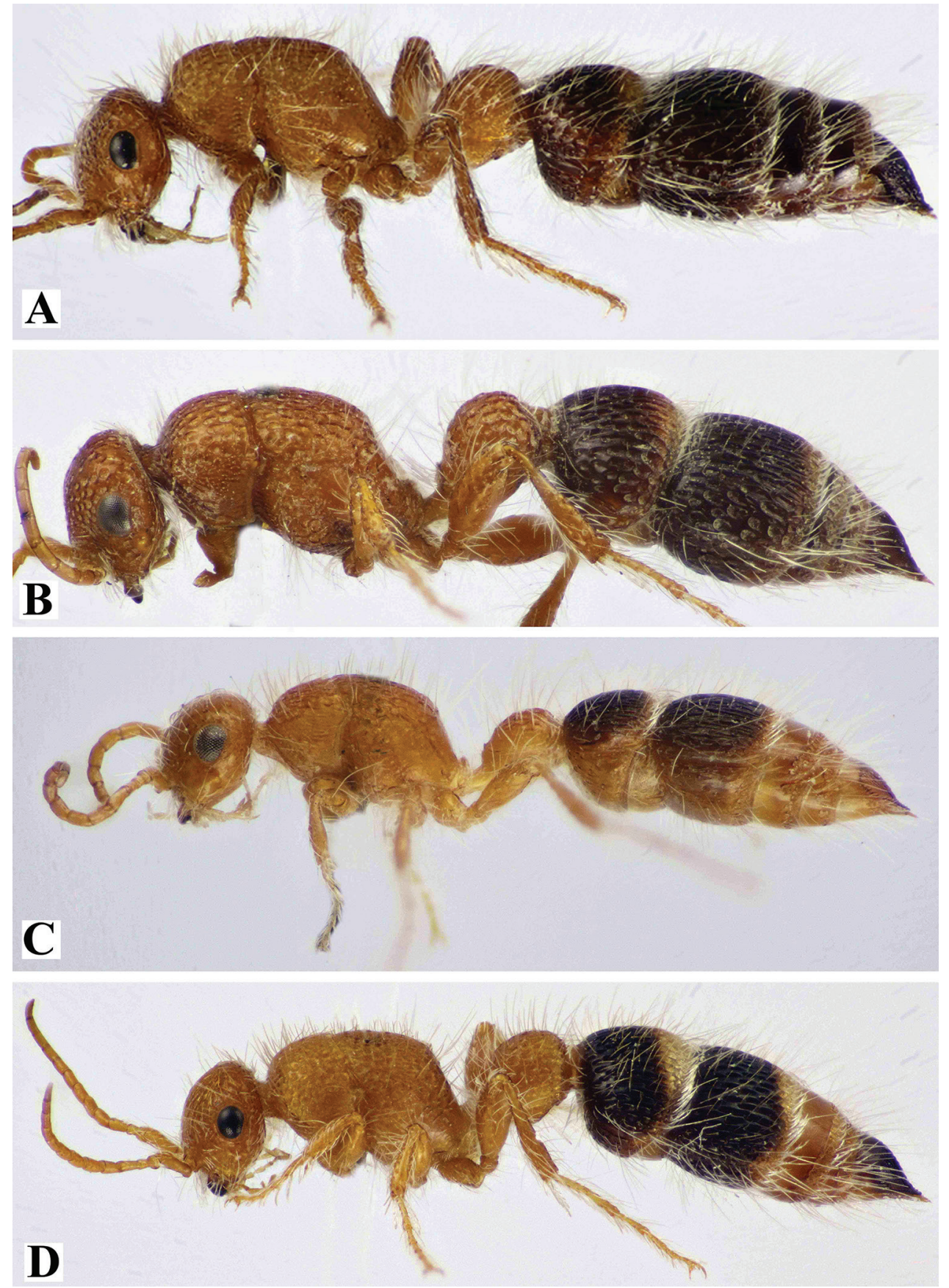

Figure 4. Lateral habitus. A Micatagla fuscogaster Soliman \& Gadallah, sp. nov B M. reemae Gadallah \& Soliman, sp. nov. C M. saudita Soliman \& Gadallah, sp. nov. D M. similis Gadallah \& Soliman, sp. nov. 
Variation. In one paratype specimen T3 with greatly reduced apical yellow band; some specimens shorter than the holotype specimen in length $(4.3-6.0 \mathrm{~mm})$.

Distribution. Saudi Arabia (Asir region, Garf Raydah Natural Reserve).

Etymology. The specific name 'fuscogaster' refers to the dark reddish brown colour of most of the metasoma.

\section{Micatagla reemae Gadallah \& Soliman}

Figures 4B, 5B, 6B, 7B, 8B, 9B, 10B, 11B, 12B, 13B, 14B

Material examined. Holotype 9 : Saudi Arabia, Asir (Abha, GRNR), 30.vii.2015, Hp4 (Olive 1), leg. Al Dhafer et al. [KSMA].

Diagnosis. Metasomal segments 2-6 dark brown to black (Figs 12B, 13A, 14B); head and mesosomal dorsum greatly bare (Figs 6B, 7B, 9B); T2 with setal row restricted to posteromesal part along the yellow band, absent laterally (Fig. 12B); T2 and T3 ellipsoid punctate, punctures are opened posteriorly, with strong longitudinal ridges in between (Fig. 12B).

This species resembles $M$. fuscogaster Soliman \& Gadallah in having the same body colour, apical rows of setae and yellow bands of metasomal tergites, but differs in the following: face asetose (Fig. 6B) (face covered with dense pale setae in $M$. fuscogaster (Fig. 6A)); vertex narrowly convex, semi-rounded (broadly convex in $M$. fuscogaster); mandible edentate (Fig. 6B) (with very small two teeth subapically in $M$. fuscogaster); ridges between ellipsoid punctures on T2 and T3 fine (Fig. 12B ) (coarse in $M$. fuscogaster (Fig. 12A)); T6 with eight longitudinal ridges, widely separated (Fig. 14B) (10-12 and closer in M. fuscogaster (Fig. 14A)).

Description. Female (Holotype). Body length $6.0 \mathrm{~mm}$.

Colour (Figs 4B, 5B, 12B, 14B): Head (including antennae), mesosoma, legs and first metasomal segment bright red; remaining metasoma dark brown to black, with yellow bands posteromesal margin of T2 and posterior margin of T3; mandible dark reddish brown, red basally. Eye gray; fore tibial spur yellow, mid and hind ones waxy white; T6 with black longitudinal ridges.

Pubescence (Figs 7B, 9B, 10B, 11B, 12B): Posterior margin of head, anterior margin of pronotum, as well as lateral margins of mesosoma and metasoma clothed with fine whitish setae that are short and erect at head and pronotum; anterior margin of T1 with fine, long upwardly directed setae, posterior margin of metasomal tergites with rows of silvery setae, that are somewhat less dense on T1 and restricted to the yellow area on $\mathrm{T} 2$, absent laterally.

Head (Figs 6B, 7B, 8B): In dorsal view as wide as pronotum, with thin, sharp occipital carina; face with relatively large, deep punctures, that are dense along inner margin of eyes and antennal tubercles, becoming reduced in number above, with smooth and shiny integument between punctures; face just behind vertex nearly bare medially; 


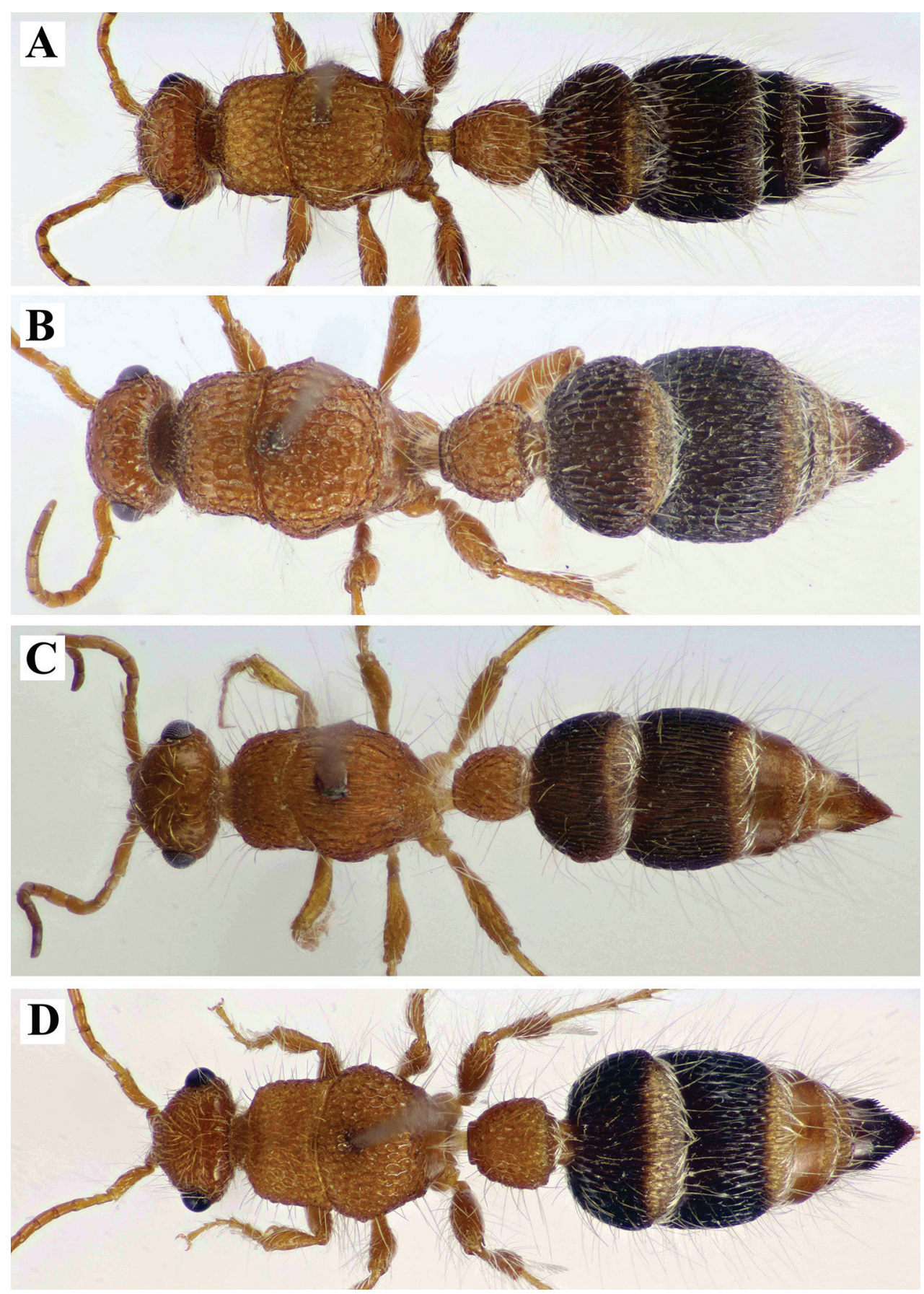

Figure 5. Dorsal habitus. A Micatagla fuscogaster Soliman \& Gadallah, sp. nov B M. reemae Gadallah \& Soliman, sp. nov. C M. saudita Soliman \& Gadallah, sp. nov. D M. similis Gadallah \& Soliman, sp. nov. 

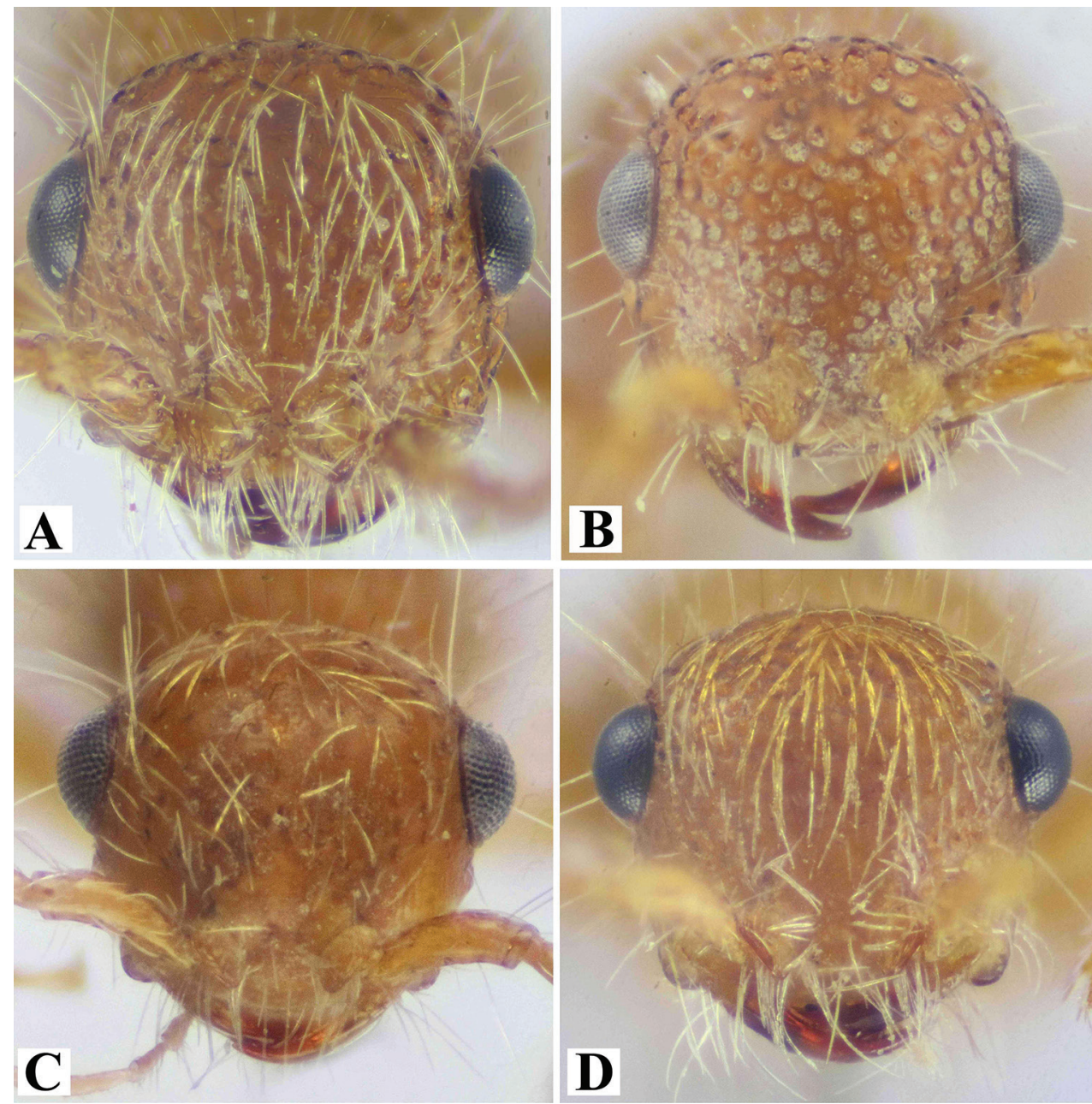

Figure 6. Frontal view of head. A Micatagla fuscogaster Soliman \& Gadallah, sp. nov B M. reemae Gadallah \& Soliman, sp. nov. C M. saudita Soliman \& Gadallah, sp. nov. D M. similis Gadallah \& Soliman, sp. nov.

vertex somewhat semi-rounded (narrowly convex); eye small, weakly bulged laterally when seen in dorsal or frontal view, located above mid line between clypeus and vertex when seen in frontal view; distance between antennal tubercles about as long as tubercle length; malar space about as long as eye height; scape of antenna about $2.5 \times$ as long as F1; F1 slightly longer than F2. Clypeus thin and broad, slightly emarginate at free margin; mandible relatively thick, edentate.

Mesosoma (Figs 9B, 10B): Pronotum about $1.7 \times$ as wide as long at its maximum width, densely foveate dorsally, with anterior margin gently declivous, humeral angle rounded and posterior margin slightly concave; remainder of mesosomal dorsum densely foveate-reticulate, fovea larger than those on pronotum; posterior face 

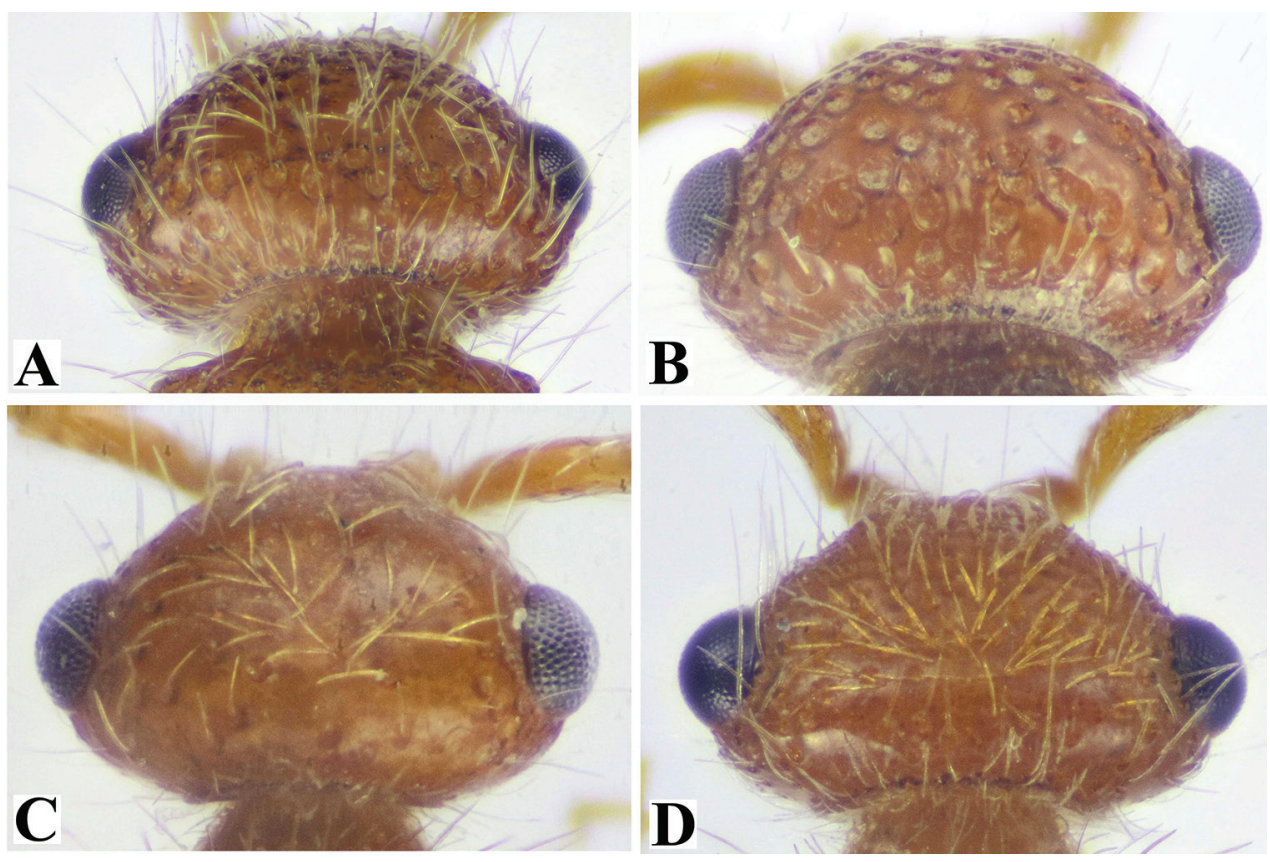

Figure 7. Dorsal view of head. A Micatagla fuscogaster Soliman \& Gadallah, sp. nov B M. reemae Gadallah \& Soliman, sp. nov. C M. saudita Soliman \& Gadallah, sp. nov. D M. similis Gadallah \& Soliman, sp. nov.

of propodeum gently declivous, somewhat smooth and impunctate; pronotal lateral face faintly wrinkled; mesopleuron superficially foveolate; metapleuron nearly smooth. Outer hind tibial spur about $0.5 \times$ length of hind basitarsus. Mesosternum with two parallel-sided, very close lobes enclosing a thin-carinated oval area, extending in the middle just above bases of mesocoxae and reaching bases of metacoxae straightly. Mesosternum punctate, punctures about 1 diameter apart.

Metasoma (Figs 11B, 12B, 13B, 14B): T1 pear-shape, about as long as maximal width, densely and closely foveate; T2 bell-shape, about $1.3 \times$ as wide as long, with yellow band widened medially and absent laterally; T2 and T3 on disc longitudinally strigate, with large ellipsoid puncture in between, punctures are closed on T2 and opened posteriorly on $\mathrm{T} 3$, contiguous with each other, laterally both tergites are densely foveate; T4 and T5 with rows of coarse and very close setiferous punctures; T6 basally with about eight longitudinal, widely separated ridges, broadly rounded at apex, with sharp spaced teeth laterally, extending from near base to upper two thirds, becoming minute to serrate, and very close posteriorly. S2 and S3 with scattered punctures mainly laterally and medially, leaving posterior margin smooth and shiny pre-apically, S2-5 with row of fine setae along posterior margins, arise from large sockets, S4-6 smooth and shiny.

Distribution. Saudi Arabia (Asir region, Garf Raydah Natural reserve).

Etymology. This species is named in honour of the daughter "Reem" of Ahmed M. Soliman. 

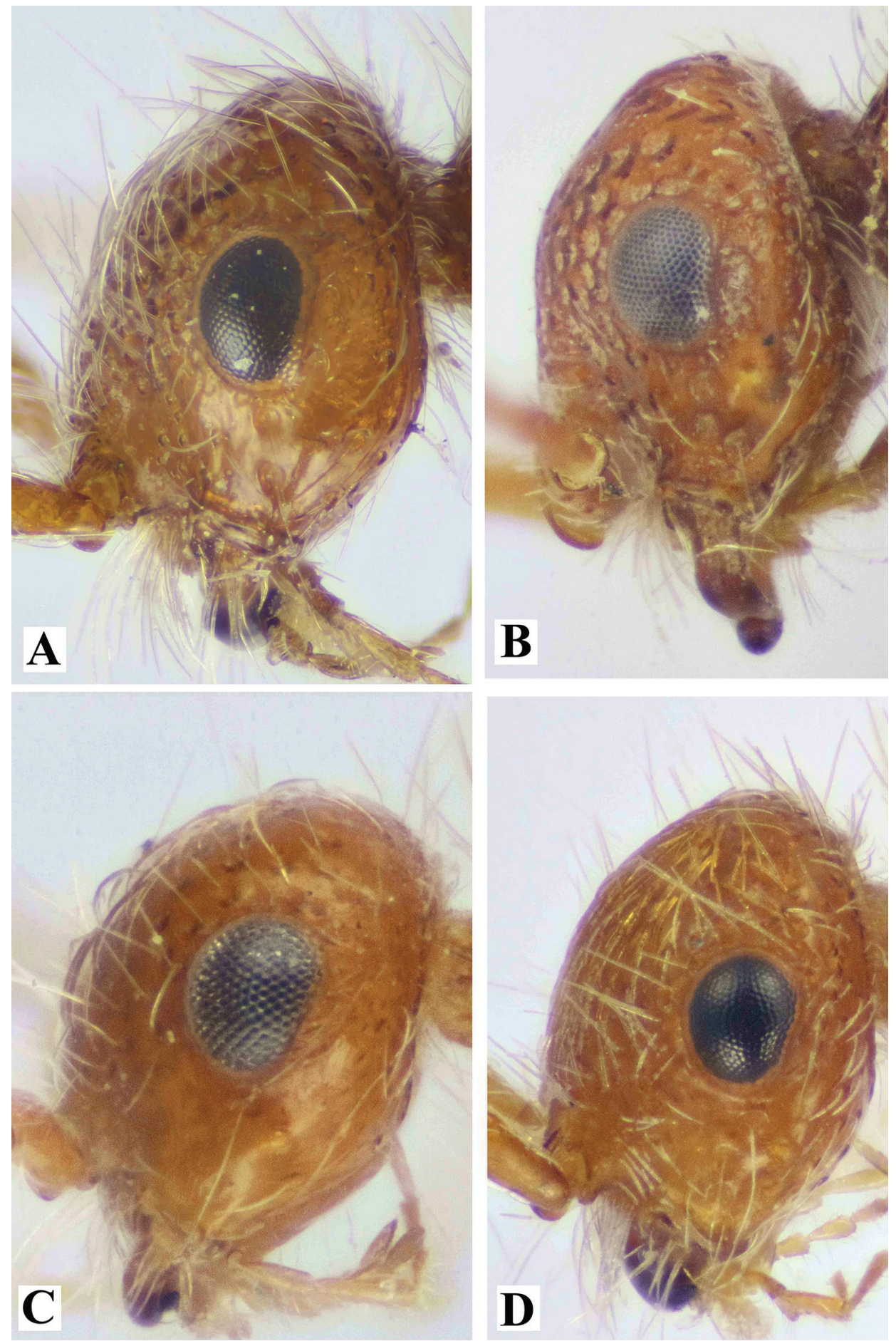

Figure 8. Lateral view of head. A Micatagla fuscogaster Soliman \& Gadallah, sp. nov B M. reemae Gadallah \& Soliman, sp. nov. C M. saudita Soliman \& Gadallah, sp. nov. D M. similis Gadallah \& Soliman, sp. nov. 


\section{Micatagla saudita Soliman \& Gadallah}

Figures 4C, 5C, 6C, 7C, 8C, 9C, 10C, 11C, 12C, 13C, 14C

Material examined. Holotype $q$ : Saudi Arabia, Riyadh (Wadi Hanifah, WHN05), 27.viii.2015, PT, leg. Abdeldayem et al. [KSMA]; Paratypes: 1 ㅇ Saudi Arabia: Riyadh (Wadi Hanifah, WHS02), 27.viii.2015, PT, leg. Abdeldayem et al. [KSMA]; 1 \&audi Arabia: Riyadh (Wadi Hanifah, WHS03), 27.viii.2015, PT, leg. Abdeldayem et al. [KSMA]; 1 ㅇ Saudi Arabia: Riyadh (Wadi Hanifah, WHS05), 27.viii.2015, PT, leg. Abdeldayem et al. [KSMA]; 1 q Saudi Arabia: Riyadh (Wadi Hanifah, WHU02), 12.x.2015, PT, leg. Abdeldayem et al. [KSMA]; 5 + Saudi Arabia: Riyadh (Wadi Hanifah, WHS01), 12.x.2015, PT, leg. Abdeldayem et al. [KSMA]; 1 + Saudi Arabia: Riyadh (Wadi Hanifah, WHS02), 12.x.2015, PT, leg. Abdeldayem et al. [KSMA]; 1 q Saudi Arabia: Riyadh (Wadi Hanifah, WHN01), 12.x.2015, PT, leg. Abdeldayem et al. [KSMA]; 2 + Saudi Arabia: Riyadh (Wadi Hanifa WHS02), 12.x.2015, PT, leg. Abdeldayem, M. et al. [EFC].

Diagnosis. Body slender; head, mesosoma and the first and 4-6 $6^{\text {th }}$ metasomal segments uniformly red (Figs 4C, 5C); T1 pear-shape (Fig. 11C); T2 and T3 dark brown, longitudinally closely strigate, both tergites with distinct yellow bands and compact (dense) setal rows along the whole posterior margins (Fig. 12C); T6 laterally with relatively small but sharp teeth, a little spaced in the middle, posterior ones minute and rounded at the apex (Fig. 14C).

The new species may be confused with M. ezzati Gadallah \& Soliman, 2014 (Egypt) (Fig. 15) in having the same body colour, T6 red with lateral teeth not excessively large and a little spaced in the middle, but differs from it by having body very slender, mesosoma striatopunctate (Fig. 9C) and T2 and T3 longitudinally strigate (Fig. 12C) (body robust, mesosoma densely punctate (Fig. 15B) and T2 and T3 ellipsoid punctate with ridges in between (Fig. 15C) in M. ezzati).

Description. Female (Holotype). Body slender, $4.0 \mathrm{~mm}$ in length.

Colour (Figs 4C, 5C, 12C, 14C): Head including antenna, mesosoma, legs and the first and $4^{\text {th }}-6^{\text {th }}$ (except lateral margins of T6, including teeth, slightly brownish); metasomal segments as well as S2 red; T2 and T3 dark brown, both tergites with welldeveloped yellow bands along posterior margin that are widened medially; S3 reddish brown; maxillary and labial palpi yellow; mandible reddish brown, red basally; fore tibial spur red, mid and hind ones waxy white.

Pubescence (Figs 6C, 10C, 11C, 12C): Body including scape of antenna and legs clothed with scattered fine and erect white setae; face with scattered procumbent palegolden setae, denser and inwardly directed on vertex, dorsum of mesosoma with similar but erect setae; posterior margin of T1-5 with row of dense silvery setae, directed towards middle.

Head (Figs 6C, 7C, 8C): In dorsal aspect scarcely wider than the maximal width of pronotum (about $1.1 \times$ ), with thin occipital carina; face and vertex with scattered setiferous punctures, vertex broadly convex; gena and malar area nearly smooth; eye small, somewhat bulged laterally when seen in front or dorsal view, located above mid line between clypeus and vertex when seen in front view; distance between antennal 


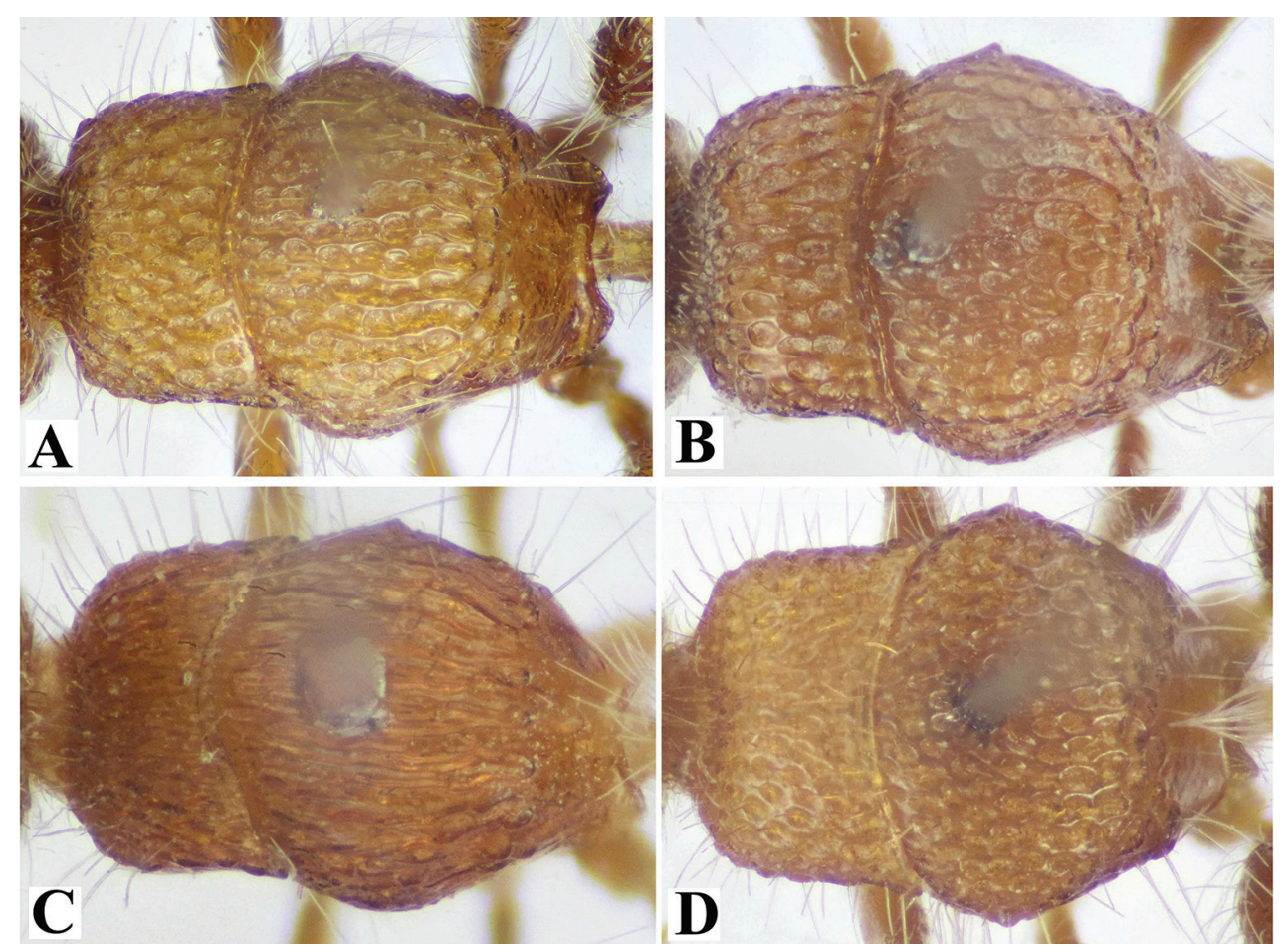

Figure 9. Dorsal aspect of mesosoma. A Micatagla fuscogaster Soliman \& Gadallah, sp. nov. B M. reemae Gadallah \& Soliman, sp. nov. C M. saudita Soliman \& Gadallah, sp. nov. D M. similis Gadallah \& Soliman, sp. nov.

tubercles about as long as tubercle length; malar space hardly longer than eye height (about $1.1 \times$ ); scape of antenna about $2.5 \times$ as long as F1; F1 as long as F2. Clypeus broad, with apical half nearly smooth and gently bent toward the mouth, basal part of clypeus with scattered setiferous punctures; mandible edentate.

Mesosoma (Figs 9C, 10C): Pronotum shallowly foveate dorsally, weakly rugose laterally, rectangular (about $1.65 \times$ as wide as long at maximum width), with anterior margin gently declivous, humeral angle rounded and posterior margin broadly concave; remainder of mesosomal dorsum setiferous striatofoveate; posterior face of propodeum gently declivous, smooth and impunctate; mesopleuron superficially foveolate; metapleuron smooth above, and weakly transversely ridged below. Inner hind tibial spur about $0.65 \times$ as long as hind related basitarsus.

Metasoma (Figs 11C, 12C, 13C, 14C): T1 pear-shape, as long as its maximal width, shallowly setiferous foveate; T2 semicircular, about $1.5 \times$ as wide as long, with yellow band remarkably widened medially; T2 and T3 longitudinally strigate; ridges on T3 more regular and closer than those of T2; T4 and T5 posteriorly with row of very close ellipsoid punctures; T6 with weak, scattered and widely interrupted brown ridges, narrowly rounded at apex, laterally with small but sharp teeth, becoming minute towards apex. S2 and S3 smooth except laterally with scattered setiferous punctures, with row of long scat- 


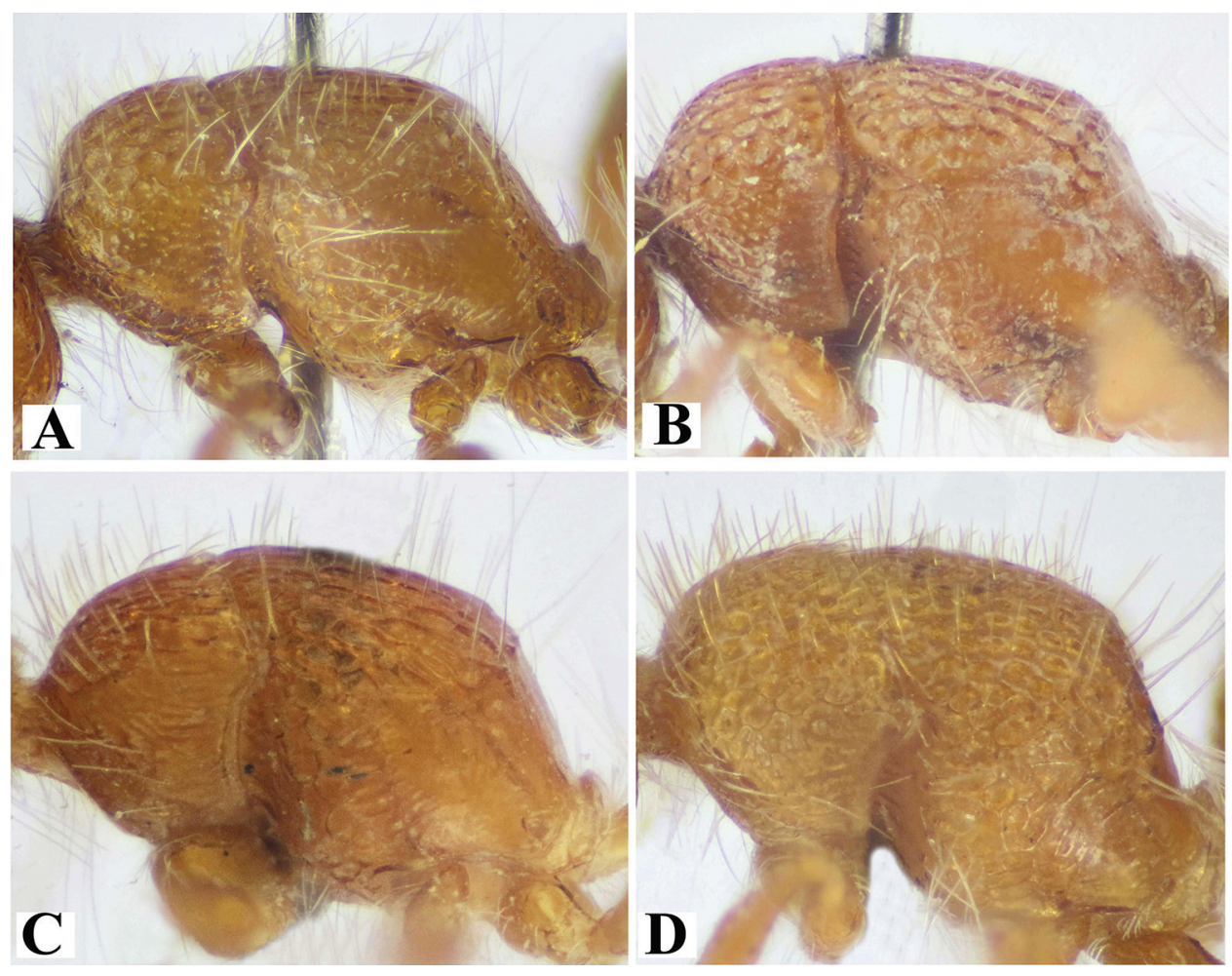

Figure 10. Lateral aspect of mesosoma. A Micatagla fuscogaster Soliman \& Gadallah, sp. nov. B $M$. reemae Gadallah \& Soliman, sp. nov. C M. saudita Soliman \& Gadallah, sp. nov. D M. similis Gadallah $\&$ Soliman, sp. nov.

tered setae along posterior margins; $\$ 4-5$ smooth and shiny except posteriorly with row of setiferous punctures; hypopygium with setiferous punctures on posterior half.

Variation. Some paratype specimens are longer, about $4.8-5.5 \mathrm{~mm}$. In some specimens T6 slightly darker, yellow-brown; face with darker golden setae.

Distribution. Saudi Arabia (Riyadh region).

Etymology. The specific name 'saudita' is a Latinized adjective in the feminine gender derived from the country of the type locality, Saudi Arabia.

\section{Micatagla similis Gadallah \& Soliman}

Figures 4D, 5D, 6D, 7D, 8D, 9D, 10D, 11D, 12D, 13D, 14D

Material examined. Holotype $\odot$ : Saudi Arabia, Al-Baha, (Al-Mukhwah, Shada Al-Ala Natural Reserve), 31.vii.2015, PT4 (Acacia 2), leg. Al Dhafer et al. [KSMA]. Paratypes: 1 ㅇ Saudi Arabia: Al-Baha (Amadan Madaq), 19.v.2010, leg. M.R. Sharaf [KSMA]; 1 우 Saudi Arabia: Al-Baha, (Al-Mukhwah, Shada Al-Ala Natural Reserve), 23.iv.2014, PT2 (Cactus 2), leg. Al Dhafer et al. [KSMA]; 1 Saudi Arabia: Al-Baha, (Al-Mukhwah, 


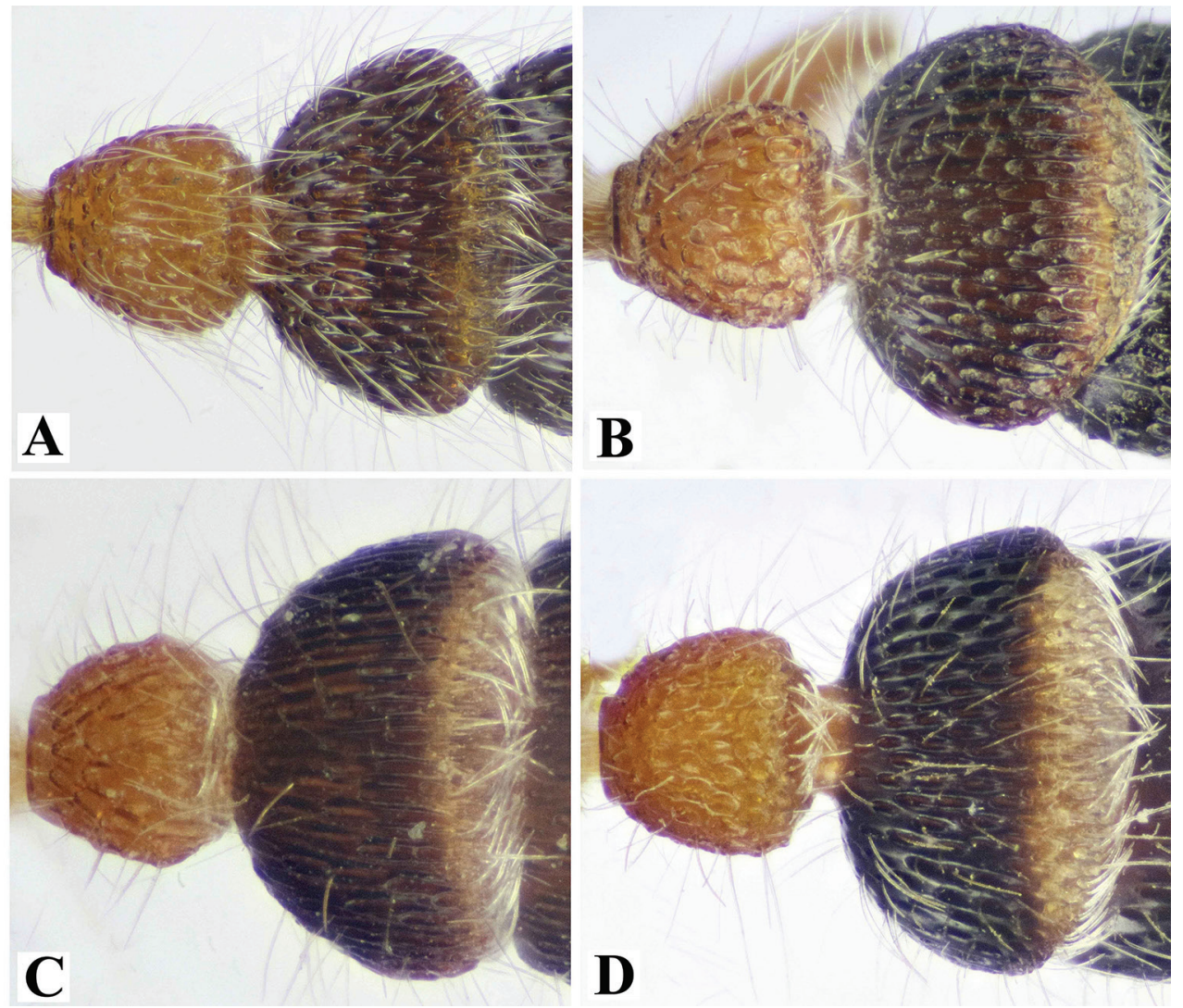

Figure II. Metasomal T1 and T2. A Micatagla fuscogaster Soliman \& Gadallah, sp. nov. B M. reemae Gadallah \& Soliman, sp. nov. C M. saudita Soliman \& Gadallah, sp. nov. D M. similis Gadallah \& Soliman, sp. nov.

Shada Al-Ala Natural Reserve), 23.iv.2014, PT4 (Acacia 1), leg. Al Dhafer et al. [KSMA]; 5 q Saudi Arabia: Al-Baha, (Al-Mukhwah, Shada Al-Ala Natural Reserve), 23.viii.2014, PT4 (Acacia 1), leg. Al Dhafer et al. [KSMA]; 1 ㅇ Saudi Arabia: Al-Baha, (Al-Mukhwah, Shada Al-Ala Natural Reserve), 2.iii.2015, PT2 (Cactus 2), leg. Al Dhafer et al. [KSMA]; 1 + Saudi Arabia: Al-Baha, (Al-Mukhwah, Shada Al-Ala Natural Reserve), 2.iii.2015, PT5 (Acacia 2), leg. Al Dhafer et al. [KSMA]; 2 ㅇ Saudi Arabia, AlBaha, (Al-Mukhwah, Shada Al-Ala Natural Reserve), 3.v.2015, PT2 (Cactus 2), leg. Al Dhafer et al. [KSMA]; 4 ㅇ Saudi Arabia: Al-Baha, (Al-Mukhwah, Shada Al-Ala Natural Reserve), 3.v.2015, PT3 (Cactus 3), leg. Al Dhafer et al. [KSMA]; 2 q Saudi Arabi: Al-Baha, (Al-Mukhwah, Shada Al-Ala Natural Reserve), 31.vii.2015, PT2 (Cactus 2), leg. Al Dhafer et al. [KSMA]; 3 + Saudi Arabia: Al-Baha, (Al-Mukhwah, Shada Al-Ala Natural Reserve), 31.vii.2015, PT4 (Acacia 1), leg. Al Dhafer et al. [KSMA]; 49 Saudi Arabia: Al-Baha, (Al-Mukhwah, Shada Al-Ala Natural Reserve), 31.vii.2015, PT5 (Acacia 2), leg. Al Dhafer et al. [KSMA]; 1 \% Saudi Arabia: Al-Baha, (Al-Mukhwah, Shada Al-Ala Natural Reserve), 15.xi.2015, PT4 (Acacia 2), leg. Al Dhafer et al. [KSMA]. 

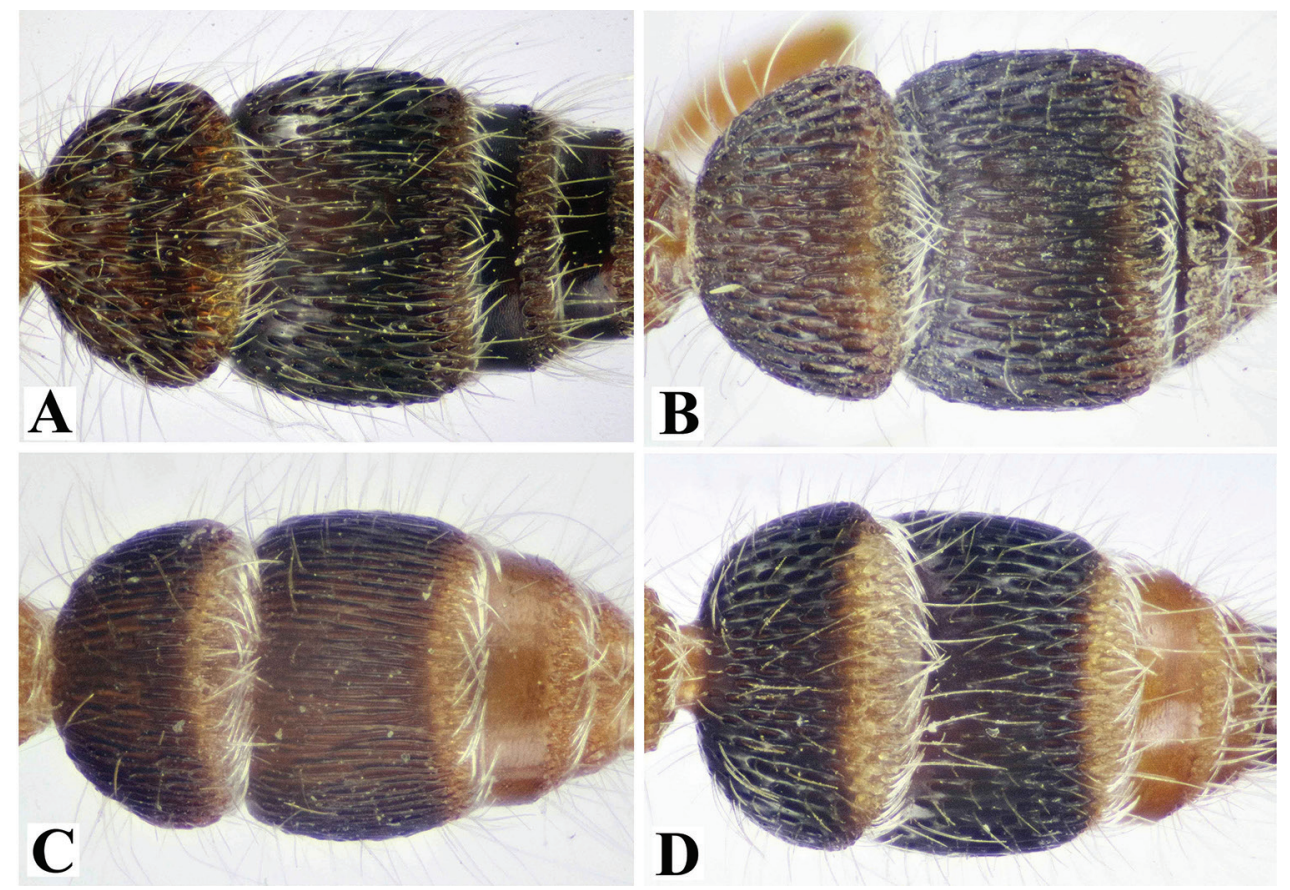

Figure 12. Metasomal T2-T5. A Micatagla fuscogaster Soliman \& Gadallah, sp. nov. B M. reemae Gadallah \& Soliman, sp. nov. C M. saudita Soliman \& Gadallah, sp. nov. D M. similis Gadallah \& Soliman, sp. nov.

Diagnosis. Body relatively slender; face with bright red setae (Fig. 6D); mesosomal dorsum slightly longer than wide; propodeum with posterior face gently declivous, oblique (Fig. 10D); T2 and T3 with relatively broad yellow bands along their posterior margins (Fig. 12D); T1 globular, as long as wide (Fig. 11D); T2 and T3 with closed ellipsoid punctures bordered with coarse ridges, with broad yellow band, maximal thickness of yellow band on T2 about $1.3 \times$ as long as eye height (Fig. 12D); T6 with broad triangular lateral teeth, becoming minute to meaningless posteriorly (Fig. 14D).

This species may be confused with M. zavattarii (Invrea, 1950) (Fig. 16) (examined material received from Guido Pagliano, labelled: Rosso Mauritanie, leg. Amiet, 26.i.1964, RO59) in having the same body colour and sculpture, but it differs by the following characters: body relatively slender, with mesosomal dorsum longer than wide, covered on head and mesosoma with bright red setae (Figs 5D, 6D, 9D, 10D) (robust, with mesosomal dorsum as long as broad, covered with white setae in $M$. zavattarii (Fig. 16A, B)); propodeal posterior face oblique (Fig. 10D) (vertical in $M$. zavattarii (Fig. 16B)); T2 bell-shape, with lateral side broadly curved (Fig. 12D) (semicircular, with lateral side sharply curved in M. zavattarii (Fig. 16D)); T2 with coarse ridges (Fig. 12D) (fine in zavattarii (Fig. 16D)); T6 with broad triangular lateral teeth (Fig. 14D) (with minute (meaningless) teeth in zavattarii (Fig. 16E)).

Description. Female (Holotype). Body length $6.0 \mathrm{~mm}$. 


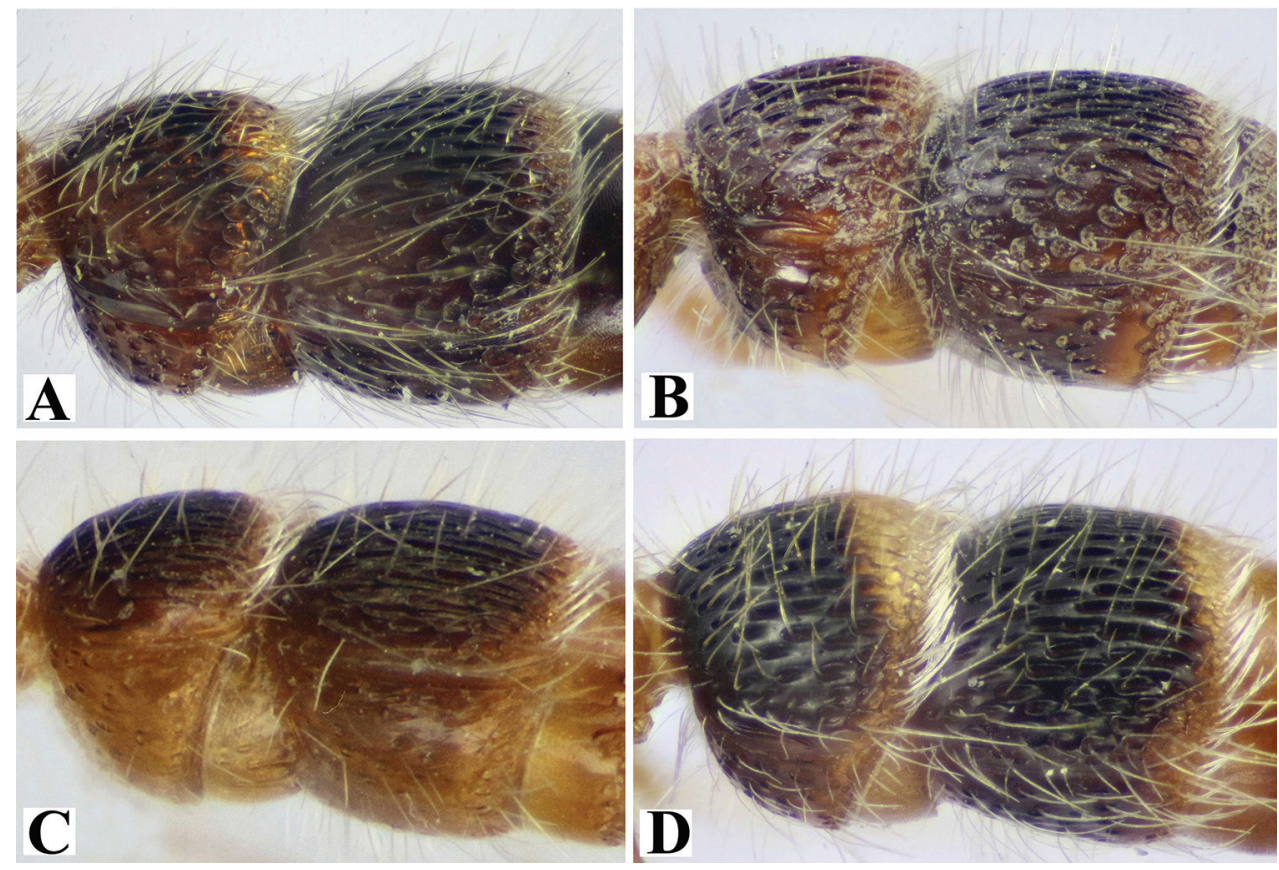

Figure 13. Lateral aspect of second and third mesosomal segments. A Micatagla fuscogaster Soliman \& Gadallah, sp. nov B M. reemae Gadallah \& Soliman, sp. nov. C M. saudita Soliman \& Gadallah, sp. nov. D $M$. similis Gadallah \& Soliman, sp. nov.

Colour (Figs 4D, 5D, 14D): Head (including antenna), mesosoma, legs and first metasomal segment red, head distinctly dark red; second and third metasomal segments black, with well-developed yellow bands at posterior margins of T2 and T3 (that widened medially in T2); S2 reddish; T4 and T5 reddish brown, with faint yellow posterior margins; T6 dark ferruginous, with black longitudinal ridges. Eye black; mandible dark reddish brown, red basally; maxillary and labial palpi yellow; fore tibial spur red, mid and hind ones waxy white.

Pubescence (Figs 6D, 10D, 11D, 12D): Face densely covered with radiated, bright red, long fine adpressed setae, such setae (but less bright) covering mesosoma, shorter and erect laterally as well as T1; remainder of metasoma clothed with whitish, erect to semierect fine setae especially laterally; posterior margin of metasomal tergites with rows of silvery setae; legs as well clothed with such fine setae. Posterior margin of metasomal S1 with dense fine, relatively long setae; $\mathrm{S} 2-5$ with a row of fine adpressed setae.

Head (Figs 6D, 7D, 8D): In dorsal view slightly wider than pronotum, setiferous punctate (except smooth malar space), with thin and sharp occipital carina; vertex broadly convex; eye relatively small, but distinctly bulged laterally when seen in front or dorsal view, located above mid line between clypeus and vertex when seen in front view; malar space relatively long, about $1.3 \times$ as long as eye height; antennal tubercles away from each other by a distance shorter than tubercle length; antenna with scape about $2.5 \times$ as long as F1, distinctly elbowed; F1 as long as F2 (that is slightly widened 

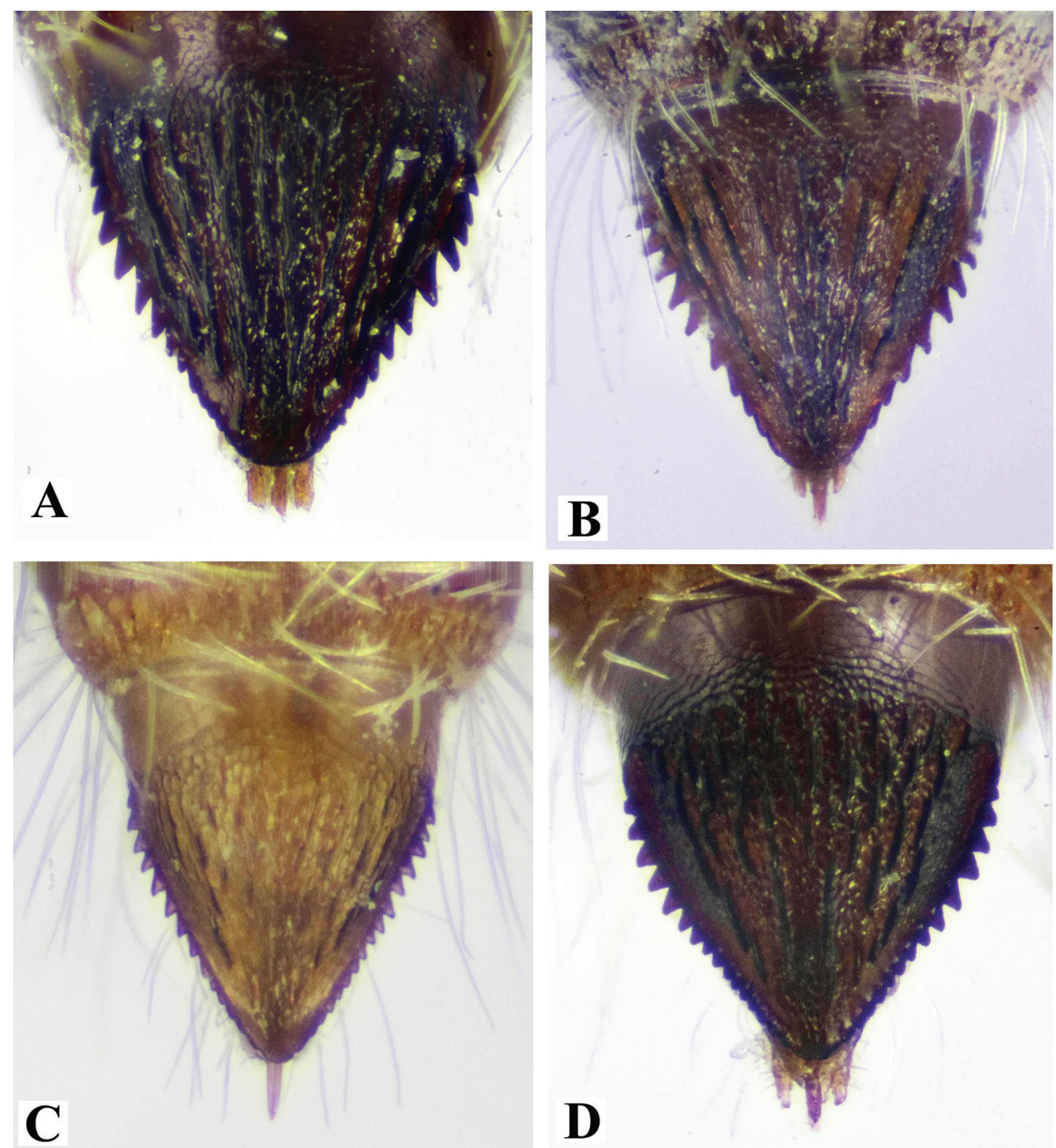

Figure 14. Metasomal T6. A Micatagla fuscogaster Soliman \& Gadallah, sp. nov. B M. reemae Gadallah \& Soliman, sp. nov. C M. saudita Soliman \& Gadallah, sp. nov. D M. similis Gadallah \& Soliman, sp. nov.

apically). Clypeus broad, setiferous punctate basally, with smooth and bent apical portion; mandibles somewhat thin, edentate.

Mesosoma (Figs 9D, 10D): Mesosomal dorsum slightly longer than wide at mesopleuron; pronotum about $1.7 \times$ as wide as long, with gently declivous anterior margin, rounded humeral angle and broadly concave posterior margin; pronotum with dense rounded setiferous foveolae dorsally, superficially foveolate laterally; rest of mesosoma setiferous foveate-reticulate; propodeal posterior face gently declivous, smooth. Mesopleuron superficially foveolate; metapleuron superficially foveolate above, and weakly transversely ridged below; mesosternum smooth basally, punctate laterally, leaving an 


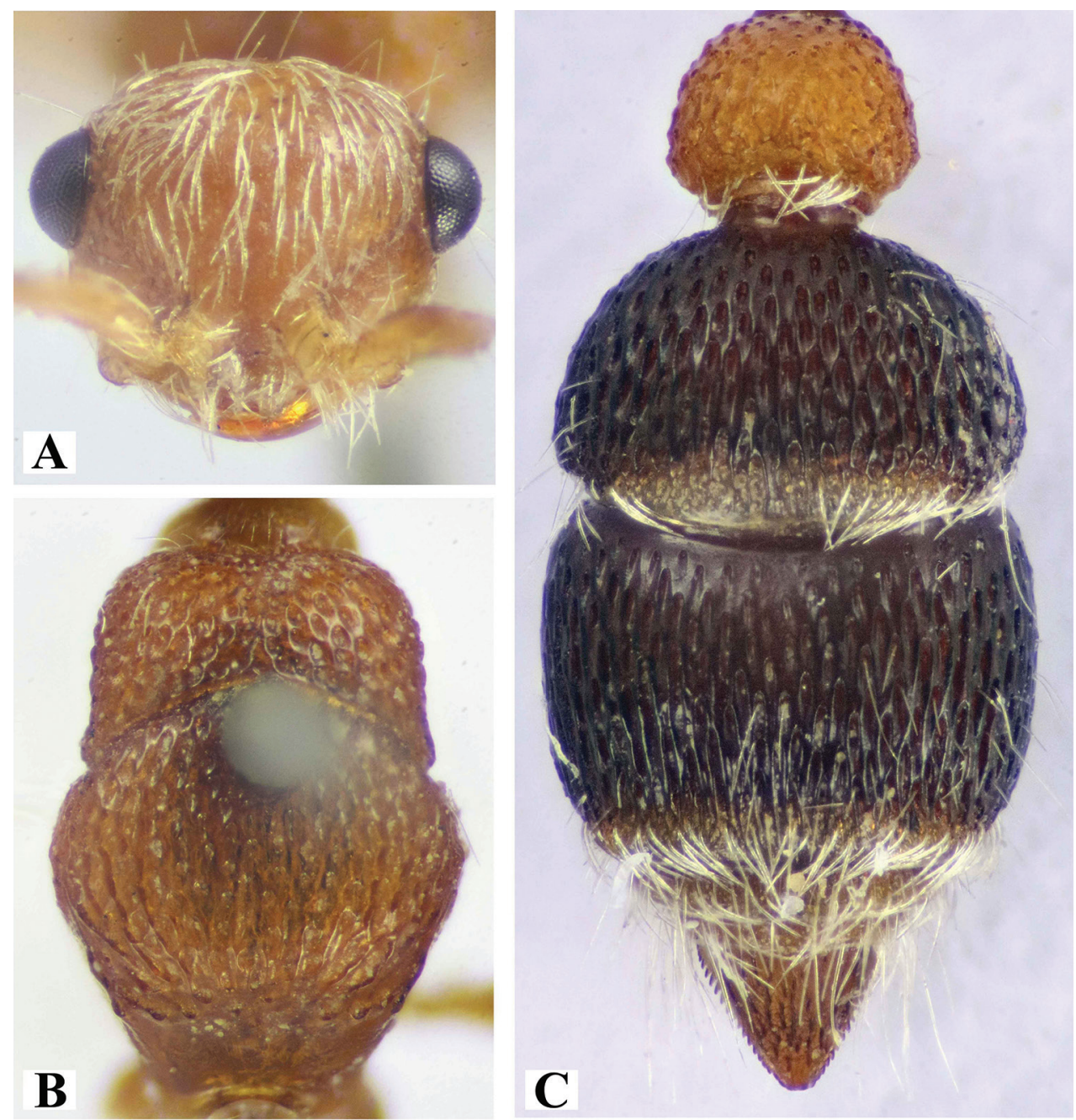

Figure I5. Micatagla ezzati Gadallah \& Soliman, 2014. A Frontal view of head B dorsal aspect of mesosoma $\mathbf{C}$ dorsal aspect of metasoma.

oval smooth and shiny area medially. Hind outer tibial spur about $0.6 \times$ as long as related basitarsus.

Metasoma (Figs 11D, 12D, 13D, 14D): T1 globular, slightly wider than long, densely foveate; T2 bell-shape, with closed ellipsoid punctures; T3 longitudinally ridged, with ellipsoid punctures in between [as in T2 but punctures more elongate here]; T4 and T5 smooth to very finely sculptured, with dense close longitudinal sockets posteriorly; T6 densely ridged, ridges are interrupted, rounded apically, laterally with relatively short and dense, very close teeth at basal two thirds, becoming minute and meaningless posteriorly. S1 nearly smooth; S2 and S3 (except smooth and shiny posterior margin) with moderately scattered punctures that are irregularly separated.

Etymology. The Latin name similis (adjective) refers to the similarity of this species with Micatagla zavattarii (Invrea). 

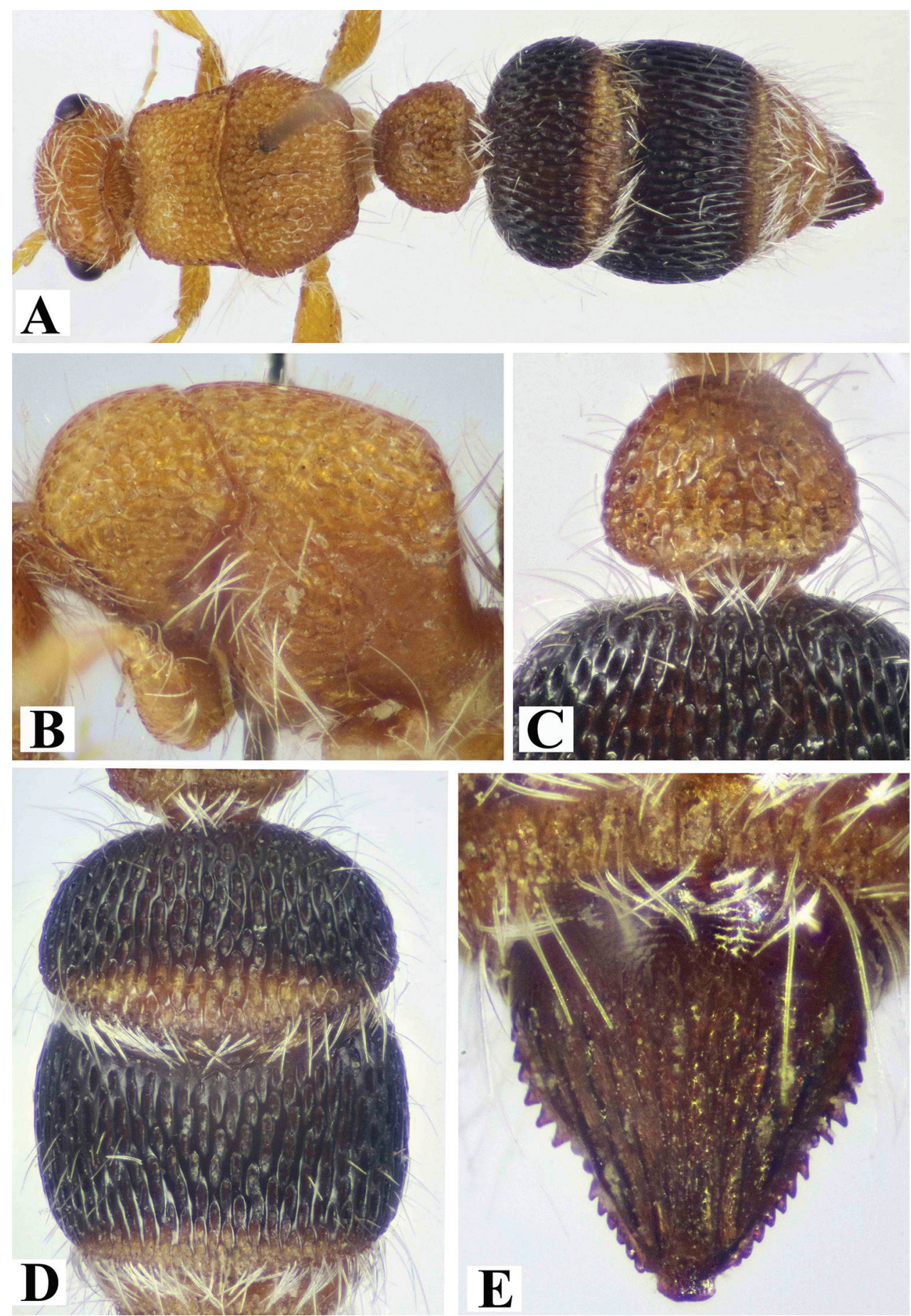

Figure 16. Micatagla zavattarii (Invrea, 1950). A Dorsal habitus B lateral aspect of mesosoma C metasomal T1 and part of T2 D metasomal T2 and T3 E matasomal T6. 


\section{Acknowledgements}

Sincere gratitude to Guido Pagliano for sending us a Micatagla zavattarii specimen to examine. Also, many thanks to Prof. Lynn Kimsey (reviewer) for her valuable comments and criticisms on the manuscript. We thank members of the King Saud University Museum of Arthropods for their help in collecting the specimens. Sincere appreciation extended to the Deanship of Scientific Research at King Saud University for funding this research group number RGP-1437-009.

\section{References}

Argaman Q (1994) Generic synopsis of Apterogyninae (Hymenoptera: Apterogynidae). Folia Entomologica Hungarica 55: 41-48.

Gadallah NS, Soliman AM (2014) The genus Micatagla Argaman, 1994 in Egypt, with three new species and a new record (Hymenoptera, Bradynobaenidae, Apterogyninae). ZooKeys 397: 71-81. https://doi.org/10.3897/zookeys.397.6768

Harris RA (1979) A glossary of surface sculpturing. Occasional Papers in Entomology 28: 1-31.

Lo Cascio P, Pagliano G (2014) A new species of Micatagla from Socotra Island (Hymenoptera: Bradynobaenidae: Apterogyninae). Acta Entomologica Musei Nationalis Pragae 54 (supplementum): 423-427.

Pagliano G (2002) Revisione della sottofamiglia Apterogyninae (Hymenoptera: Bradynobaenidae). Museo Regionale di Scienze Naturali di Torino, Monografie 34: 1-387.

Pagliano G, Romano M (2012) Three new species of African Apterogyninae from Kenya, Namibia and Senegal (Insecta, Hymenoptera, Bradynobaenidae). Naturalista Valtellinese, Atti Museo Civico Storia naturale Morbegno 23: 15-41.

Pagliano G, Romano M (2018) World list of all known species of Bradynobaenidae (Hymenoptera). Atti Museo Civico Storia natural Morbegno 28: 15-46. 